\title{
Optic disk pit maculopathy: current management strategies
}

This article was published in the following Dove Press journal:

Clinical Ophthalmology

\section{Irini Chatziralli \\ Panagiotis Theodossiadis George P Theodossiadis}

2nd Department of Ophthalmology, University of Athens, Attikon Hospital, Athens, Greece
Correspondence: George

$P$ Theodossiadis

2nd Department of Ophthalmology, University of Athens, Attikon Hospital,

13 Lykiou Street, 10674 Athens, Greece

Tel +30 2I 07257585

$\mathrm{Fax}+302107295318$

Email theodossiadisg@ath.forthnet.gr
Introduction: Optic disk pit (ODP) is a rare congenital abnormality of the optic nerve head and can lead to visual impairment when macular detachment occurred. Recent advances in retinal imaging brought new insights into the pathophysiology of the disease, while new therapeutic options have been also described.

Methods: We made a comprehensive search of the literature regarding the current treatment modalities for the treatment of ODP maculopathy.

Results: Although there have been reported some cases of spontaneous resolution, current management of ODP maculopathy involves several surgical approaches. The most commonly used treatment alternative for ODP maculopathy management is vitrectomy, either alone or in combination with other treatment modalities, such as gas tamponade or laser photocoagulation. Other options, such as scleral buckling and inner fenestration, are also used, based on the recent findings about pathophysiology of the disease.

Conclusion: The management of ODP maculopathy remains challenging. Even though there are further advances in the understanding of the disease pathophysiology, the applied treatment is not single and therapeutic modalities differ in the success rate, related to the anatomical and functional results.

Keywords: optic disk pit, treatment, laser, gas tamponade, vitrectomy, scleral buckling

\section{Introduction}

Optic disk pit (ODP) is a rare congenital abnormality of the optic nerve head. ${ }^{1}$ It typically appears as a unilateral, small, oval, hypo-pigmented gray-white excavation of the optic disk, most commonly located at the temporal or inferotemporal segment of the optic disk, although it can be rarely found centrally or along the nasal side of the optic disk, while $15 \%$ of ODP were found to be bilateral. ${ }^{1-3}$ The incidence of ODP has been reported about one in 10,000 without gender predilection. ${ }^{1,2}$

ODP is usually asymptomatic, but it can be associated with arcuate scotomas or enlarged blind spot, especially when it is large. ${ }^{1,2}$ Vision is typically unaffected, while reduction in vision may occur in a frequency ranging from $25 \%$ to $75 \%$, when serous macular detachment appears (Figure 1). In such cases, the visual acuity is commonly $20 / 70$ or even much worse in the affected eye. ${ }^{2}$ The coexisting macular detachment especially in long-standing cases can be associated with cystoid changes, lamellar or full-thickness macular holes, and retinal pigment epithelium atrophy, leading to irreversible visual impairment with generally poor prognosis and a final visual acuity of 20/200 or worse. . $^{2,5}$

Regarding the pathophysiology of ODP maculopathy and the origin of fluid, the exact mechanism remains unclear. It has been supported that either vitreous or cerebrospinal fluid (CSF) may be the causes of macular detachment in eyes with ODP. ${ }^{6-8}$ 

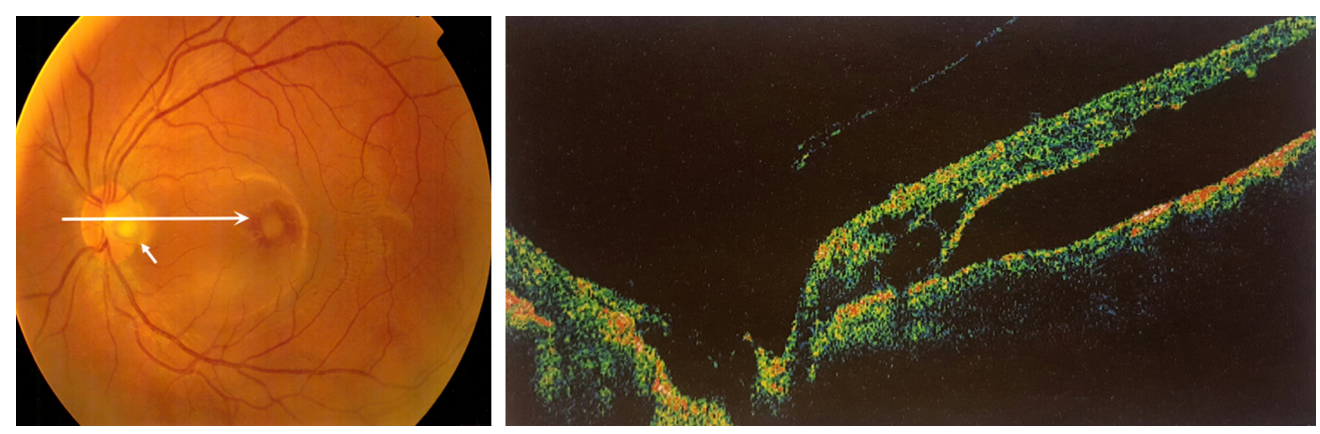

Figure I Color fundus photo and optical coherence tomography, showing optic disk pit (white arrows) and macular elevation.

In the first case, where the vitreous is considered to be the source of fluid in ODP maculopathy, the exerted pre-existing vitreous traction on the macula and optic disk may lead to the development of a negative pressure with subsequent entrance of fluid through the ODP into the submacular space. ${ }^{6,8}$ The other proposed mechanisms involve the direct communication of the macular schisis cavity/subretinal space and subarachnoid space through the ODP entrance. The communication between these two entities permits the entrance of CSF to the intra- and subretinal space through the ODP defect. ${ }^{2,9,10}$ This view was also supported by Ohno-Matsui et al, ${ }^{11}$ who were also able to see the subarachnoid space just posterior to the bottom of the ODP using swept-source optical coherence tomography (OCT), even though no direct communication was noticed between subretinal and subarachnoid space. It is worthy to note that irrespective of the origin of fluid, it has been postulated that the fluid can move through the ODP to the sub-internal limiting membrane (sub-ILM) space, ganglion cell layer, and inner and outer nuclear layers or directly to the subretinal space. ${ }^{12}$ Additionally, in eyes with ODP maculopathy, the movement of fluid between the vitreous cavity and the subarachnoid space into the subretinal space was enhanced by the observation of gas and silicone oil migration into the subretinal and intracranial space, respectively, after pars plana vitrectomy (PPV). ${ }^{13,14}$ Advances in retinal imaging shed light into the pathogenesis of ODP maculopathy, and it was supported that glial tissue may also play a role in ODP maculopathy. Specifically, Gowdar et al ${ }^{15}$ using enhanced depth imaging through the ODP showed that the existing gap in the lamina cribrosa appeared to be filled with a heterogenous reflective lesion, suggesting to be glial tissue.

Since the origin of fluid in ODP maculopathy is not clear, it is not possible to differentiate the exact origin of fluid, either from SAS or from vitreous. Therefore, no single treatment has been universally accepted due to the challenging nature of the retinal elevation. Treatment alternatives for ODP maculopathy include conservative management, laser photocoagulation, macular buckling surgery, gas tamponade, or vitrectomy with and without ILM peeling, while vitrectomy can also be combined with gas tamponade or laser photocoagulation. ${ }^{16}$ In light of the above, the purpose of this review is to analyze the treatment strategies for the management of ODP maculopathy, emphasizing the current treatment alternatives.

\section{Initial treatment modalities for the management of ODP maculopathy}

Conservative treatment and laser photocoagulation were first used for ODP maculopathy therapy. The initial recommendation for ODP treatment used to be conservative management. This view was also encouraged by the fact that spontaneous resolution of ODP was noticed in some cases in a percentage of 1-2. ${ }^{17-19}$ However, since the natural course of the disease and fluid permanent existence resulted in visual impairment and poor final outcome, several surgical interventions were adopted. ${ }^{20}$

Laser photocoagulation has been first used as a treatment alternative for the management of ODP. Laser spots were applied temporally to the optic disk and the laser scars, which are produced and act as a barrier between the ODP and the subretinal space, preventing the entrance of fluid into the macula., ${ }^{2,21}$ The most common applied laser was the argon blue-green one, although green and krypton lasers have also been used. ${ }^{22,23}$ It is worthy to mention that great care should be taken during photocoagulation, so as not to damage the retinal layers in the macular area. The results after laser photocoagulation were variable. Authors applying this technique reported absorption of the fluid and reattachment of the retina in some patients, ${ }^{21}$ but the treatment had commonly very low success rate, while significant visual field defects were reported and visual acuity was not recovered. ${ }^{4,12,24}$ Especially in cases where schisis is coexisted with macular detachment, 
Lincoff et al found that laser application showed either no response to this treatment or slight improvement. ${ }^{4,25}$ The low success rate of laser photocoagulation in ODP maculopathy was probably due to the absorption of laser energy mainly by the retinal pigment epithelium and the choroid, leaving unaffected the coexisting macular schisis. ${ }^{23}$ It is worthy to mention that the likelihood of successful laser outcome may be determined by the exact location and the amount of laser application. $^{26}$

\section{Current treatment modalities for the management of ODP maculopathy}

Nowadays, PPV is the treatment of choice for ODP maculopathy. The rationale for using PPV is based on the theory about vitreous participation and especially the vitreous traction on the macula, both of which contribute in the appearance of ODP maculopathy. The induction of posterior vitreous detachment (PVD) by PPV and the release of the vitreous traction at the macula are the factors, which probably facilitate the absorption of the subretinal fluid. ${ }^{27-30}$ A 23 G PPV has been most commonly used, and it has been combined with laser application or ILM peeling and/or gas tamponade. Specifically, after core vitrectomy, PVD has been surgically induced by aspiration with a backflush needle. After removal of the detached vitreous gel and posterior hyaloid membrane, ILM peeling can also be performed using an intraocular endgripping forceps over the superior macular region. Peeling was extended in a circumferential manner over the macular area at an area of about two disk diameters around the fovea, without touching retinal surface. Laser application at the temporal side of the ODP is another adjunctive treatment to PPV. At the end, gas tamponade either with $\mathrm{SF}_{6}$ or with $\mathrm{C}_{3} \mathrm{~F}_{8}$ is also performed.

The so far studies using PPV for the treatment of ODP maculopathy have shown promising long-term results for both retinal re-attachment and visual improvement. ${ }^{28-39}$ The majority of studies reported high anatomical success rate of $\sim 50 \%-95 \%$ and a similar functional success rate, with visual acuity improvement in $>50 \%$ of cases. ${ }^{28-39}$ In addition, a recent study has shown that particular optical coherence tomography features of ODP maculopathy may predict the surgical outcomes after PPV. Specifically, the multilayer intraretinal and subretinal fluids were less likely to have visual success, while cases where the fluid did not extend to the macular arcade vessels had better anatomical and visual outcomes. ${ }^{40}$ Additionally, another technique related to PPV has been proposed, referring to inverted ILM-flap use to cover the optic disk, including the ODP and excluding the foveal area.
This technique has shown promising results, but the evidence was low and was based only on case reports. ${ }^{41,42}$

The so far studies support the view that PPV is an effective treatment alternative in case where the vitreous cavity is the source of fluid in ODP maculopathy. ${ }^{43}$ In cases where subretinal fluid originates from the subarachnoid space, further explanation is needed regarding the efficacy of PPV and the mechanism of its action. Additionally, a recent study has demonstrated significant reduction in macular thickness in patients with ODP maculopathy treated with PPV, an observation that needs further study. ${ }^{33}$

Another current proposed therapeutic approach for ODP maculopathy is the intravitreal gas tamponade alone or combined with laser. ${ }^{44}$ Specifically, pneumatic tamponade may cause PVD and alleviation of vitreomacular traction, which considered essential factor in the pathogenesis of the disease, as mentioned earlier. ${ }^{27}$ The additional laser application contributes to the sealing of the route of the ODP to the fovea. ${ }^{45}$ The technique was reported to have a $50 \%$ success rate using $\mathrm{SF}_{6}$ alone, but more than one injection was often necessary. ${ }^{45}$ The combination of laser photocoagulation and intravitreal gas tamponade presented a higher success rate. ${ }^{46}$ Lei et al used intravitreal $\mathrm{C}_{3} \mathrm{~F}_{8}$ and laser photocoagulation and noted resolution of fluid and improvement in visual acuity in six of the eight eyes with ODP maculopathy with a follow-up of 21-62 months after treatment. The authors suggested that gas tamponade combined with laser may be a simple, minimally invasive, and effective technique. ${ }^{46}$

Surgically, macular buckling is another alternative for the treatment of ODP maculopathy. Theodossiadis et al first used this technique and reported a success rate of $\sim 85 \%$ regarding the fluid absorption after a long mean follow-up of 13 years (Figure 2) ${ }^{43,47-50}$ In this technique, a scleral sponge is fixed at the posterior pole of the eye ball corresponding to the macula without application of additional gas, laser, or cryotherapy. The sponge fixation, which was applied at 6-12 o' clock meridian, provides compression ab externo and acts as a barrier, preventing the flow of the fluid from the ODP to the macula. ${ }^{47}$ It is worthy to note that macular buckling procedure seems to provide favorable results independent of the origin of fluid in ODP maculopathy. In cases where the fluid comes from the vitreous cavity, the macular buckling elevates the macular surface and posterior hyaloid from an inward to outward vector obstructing the entrance of fluid into the intraretinal space, also alleviating the vitreous traction, which is exerted on the macula. In contrast, in case where the fluid is postulated to originate from the subarachnoid space, the application of the sponge adjacent to the temporal side 

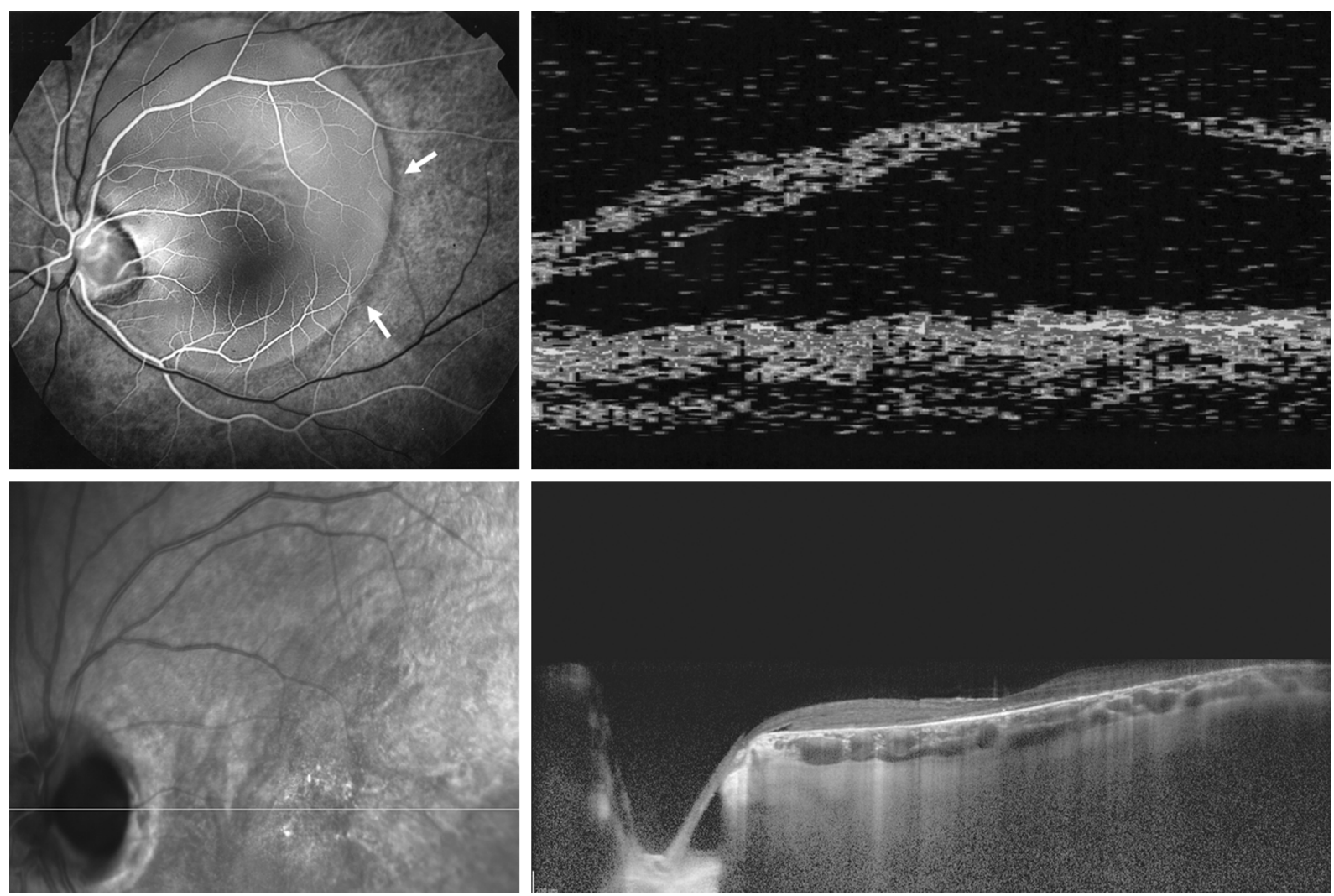

Figure 2 Optic disc pit in a male patient.

Notes: Fluorescein angiography and optical coherence tomography, showing optic disk pit at the temporal side of the disk with macular elevation (upper panel). Fundus photo and optical coherence tomography of the same patient 12 years after macular buckling procedure, where there is absorption of the fluid (lower panel). A triangularshaped space at the right side of the optic nerve is evident, and the lack of communication between this triangular space and the intraretinal layers is probably due to the sponge fixation at the nasal side of the optic nerve. White arrows represent the macular elevation.

of the scleral sheath canal of the ODP collapses the lumen of the canal and does not permit the fluid circulation from the subarachnoid space toward the subretinal space. ${ }^{45}$ It has also to be mentioned that apart from the good anatomical and functional results, this technique provided an improvement of central and peripheral visual fields (within $30^{\circ}$ of fixation).$^{50}$ However, macular buckling is considered as a difficult technique, demanding a long learning curve and that is the reason why it is not widely applied nowadays.

Other techniques that have been also applied for ODP maculopathy included inner retinal fenestration, glial tissue removal, and autologous fibrin. ${ }^{51-54}$ Ooto et $a l^{51}$ have hypothesized that despite the origin of fluid, the site of inflow into the retina seemed to be topographically related to the ODP, suggesting that redirection in the flow by inner retinal fenestration (partial thickness retinotomies) just temporal to the ODP may allow entrance of fluid into the vitreous cavity instead of the retina. The authors described that there was significant improvement in visual acuity with $56 \%$ of eyes achieving 20/30 or better, along with decrease in macular thickness, which remained stable at the 12-month follow-up, proposing this as a promising technique. ${ }^{51}$ The existing removal of glial tissue at the temporal wall of the ODP was also proposed as a procedure, which gives favorable results without recurrence of the macular fluid at the 10-year follow-up. ${ }^{52}$ The use of autologous thrombocyte method, where the autologous fibrin was prepared from the patients' whole blood and injected over the ODP followed by air-gas exchange, was also applied mainly combined with vitrectomy ${ }^{53-55}$ However, the restricted number of cases and the low level of evidence limit the use of this method.

\section{Conclusion}

The management of ODP maculopathy remains challenging. Table 1 depicts the main treatment modalities for ODP maculopathy. In patients with ODP, current management of ODP maculopathy involves surgical approaches, since the prognosis is relatively poor, leading to visual loss, if ODP left untreated, although spontaneous resolution has been reported. Nowadays, the treatment of choice for ODP maculopathy management is PPV, either alone or in combination with other treatment modalities, such as gas tamponade and 
Table I Main treatment modalities for optic disk pit maculopathy and their anatomical and functional results

\begin{tabular}{|c|c|c|}
\hline Technique & Anatomical outcome & Functional outcome \\
\hline Macular buckling & Resolution of fluid in $85 \%$ of cases & Significant improvement in visual acuity \\
\hline Intravitreal gas $\left(\mathrm{SF}_{6}\right.$ or $\left.\mathrm{C}_{3} \mathrm{~F}_{8}\right)$ & Resolution of fluid in $50 \%-75 \%$ of cases - recurrence may often occur & Significant improvement in visual acuity \\
\hline Pars plana vitrectomy & $\begin{array}{l}\text { Resolution of fluid in } 50 \%-95 \% \text { of cases - recurrence may occur in } \\
10 \%-20 \% \text { of cases }\end{array}$ & Improvement in visual acuity in $>50 \%$ of cases \\
\hline Inner retinal fenestration & Resolution of fluid in $95 \%$ of cases & Improvement in visual acuity in $56 \%$ of cases \\
\hline
\end{tabular}

laser photocoagulation. Although PPV is considered the gold standard for the treatment of ODP maculopathy, the way of its action in case where the fluid comes from subarachnoid space needs further explanation. Macular buckling acts equally well independently of the fluid origin. It has however to be noted that the procedure needs experience and a long learning curve. Moreover, recent treatment alternatives, such as inner retinal fenestration, glial tissue removal, and autologous fibrin, showed promising results, but further studies are needed to confirm these preliminary outcomes.

\section{Disclosure}

The authors report no conflicts of interest in this work.

\section{References}

1. Wiethe T. Ein Fall von angelborener Difformitaet der Sehnervenpapille. Arch Augenheilkd. 1882;11:14-19.

2. Gass JDM. Serous detachment of the macula secondary to optic disc pits. Am J Ophthalmol. 1969;67(6):821-841.

3. Theodossiadis GP, Panopoulos M, Kollia AK, Georgopoulos G. Long-term study of patients with congenital pit of the optic nerve and persistent macular detachment. Acta Ophthalmol. 1992;70(4): 495-505.

4. Theodossiadis G. Evolution of congenital pit of the optic disk with macular detachment in photocoagulated and nonphotocoagulated eyes. Am J Ophthalmol. 1977;84(5):620-631.

5. Theodossiadis GP, Theodossiadis PG, Ladas ID, et al. Cyst formation in optic disc pit maculopathy. Doc Ophthalmol. 1999;97(3-4):329-335.

6. Sugar HS. An explanation for the acquired macular pathology associated with congenital pits of the optic disc. Am J Ophthalmol. 1964;57: 833-835.

7. Irvine AR, Crawford JB, Sullivan JH. The pathogenesis of retinal detachment with morning glory disc and optic pit. Retina. 1986;6(3): $146-150$

8. Jain N, Johnson MW. Pathogenesis and treatment of maculopathy associated with cavitary optic disc anomalies. Am J Ophthalmol. 2014; 158(3):423-435.

9. Johnson TM, Johnson MW. Pathogenic implications of subretinal gas migration through pits and atypical colobomas of the optic nerve. Arch Ophthalmol. 2004;122(12):1793-1800.

10. Türkçüoğlu P, Taskapan C. The origin of subretinal fluid in optic disc pit maculopathy. Ophthalmic Surg Lasers Imaging Retina. 2016;47(3): 294-298

11. Ohno-Matsui K, Hirakata A, Inoue M, Akiba M, Ishibashi T. Evaluation of congenital optic disc pits and optic disc colobomas by swept-source optical coherence tomography. Invest Ophthalmol Vis Sci. 2013;54(12): 7769-7778.

12. Imamura $Y$, Zweifel SA, Fujiwara T, Freund KB, Spaide RF. Highresolution optical coherence tomography findings in optic pit maculopathy. Retina. 2010;30(7):1104-1112.
13. Dithmar S, Schuett F, Voelcker HE, Holz FG. Delayed sequential occurrence of perfluorodecalin and silicone oil in the subretinal space following retinal detachment surgery in the presence of an optic disc pit. Arch Ophthalmol. 2004;122(3):409-411.

14. Kuhn F, Kover F, Szabo I, Mester V. Intracranial migration of silicone oil from an eye with optic pit. Graefes Arch Clin Exp Ophthalmol. 2006;244(10):1360-1362.

15. Gowdar JP, Rajesh B, Giridhar A, Gopalakrishnan M, Hussain R, Thachil T. An insight into the pathogenesis of optic disc pit-associated maculopathy with enhanced depth imaging. JAMA Ophthalmol. 2015; 133(4):466-469.

16. Georgalas I, Ladas I, Georgopoulos G, Petrou P. Optic disc pit: a review. Graefes Arch Clin Exp Ophthalmol. 2011;249(8):1113-1122.

17. Yuen CH, Kaye SB. Spontaneous resolution of serous maculopathy associated with optic disc pit in a child: a case report. J AAPOS. 2002; 6(5):330-331.

18. Parikakis EA, Chatziralli IP, Peponis VG, et al. Spontaneous resolution of long-standing macular detachment due to optic disc pit with significant visual improvement. Case Rep Ophthalmol. 2014;5(1): 104-110.

19. Akça Bayar S, Sarıgül Sezenöz A, Yaman Pınarcı E, Yılmaz G. Spontaneous regression of optic disc pit maculopathy in a six-year-old child. Turk J Ophthalmol. 2017;47(1):56-58.

20. Sugar HS. Congenital pits in the optic disc and their equivalents (congenital colobomas and colobomalike excavations) associated with submacular fluid. Am J Ophthalmol. 1967;63(2):298-307.

21. Brockhurst RJ. Optic pits and posterior retinal detachment. Trans Am Ophthalmol Soc. 1975;73:264-291.

22. Bonnet M. Serous macular detachment associated with optic nerve pits. Graefes Arch Clin Exp Ophthalmol. 1991;229(6):526-532.

23. Theodossiadis G. Treatment of retinal detachment with congenital optic pit by krypton laser photocoagulation. Graefes Arch Clin Exp Ophthalmol. 1988;226(3):299.

24. Cox MS, Witherspoon CD, Morris RE, Flynn HW. Evolving techniques in the treatment of macular detachment caused by optic nerve pits. Ophthalmology. 1988;95(7):889-896.

25. Lincoff H, Lopez R, Kreissig I, Yannuzzi L, Cox M, Burton T. Retinoschisis associated with optic nerve pits. Arch Ophthalmol. 1988;106(1): 61-67.

26. Bakri SJ, Beer PM. Vitreoretinal surgery for optic pit associated serous macular detachment: a discussion of two cases. Int Ophthalmol. 2004;25(3):143-146.

27. Theodossiadis PG, Grigoropoulos VG, Emfietzoglou J, Theodossiadis GP. Vitreous findings in optic disc pit maculopathy based on optical coherence tomography. Graefes Arch Clin Exp Ophthalmol. 2007;245(9):1311-1318.

28. Georgalas I, Petrou P, Koutsandrea C, Papaconstadinou D, Ladas I, Gotzaridis E. Optic disc pit maculopathy treated with vitrectomy, internal limiting membrane peeling, and gas tamponade: a report of two cases. Eur J Ophthalmol. 2009;19(2):324-326.

29. Hirakata A, Inoue M, Hiraoka T, Mccuen BW. Vitrectomy without laser treatment or gas tamponade for macular detachment associated with an optic disc pit. Ophthalmology. 2012;119(4):810-818.

30. Talli PM, Fantaguzzi PM, Bendo E, Pazzaglia A. Vitrectomy without laser treatment for macular serous detachment associated with optic disc pit: long-term outcomes. Eur J Ophthalmol. 2016;26(2):182-187. 
31. Kumar A, Gogia V, Nagpal R, Roy S, Gupta S. Minimal gauge vitrectomy for optic disc pit maculopathy: our results. Indian J Ophthalmol. 2015;63(12):924-926.

32. Rizzo S, Belting C, Genovesi-Ebert F, et al. Optic disc pit maculopathy: the value of small-gauge vitrectomy, peeling, laser treatment, and gas tamponade. Eur J Ophthalmol. 2012;22(4):620-625.

33. Chatziralli I, Theodossiadis G, Panagiotidis D, Emfietzoglou I, Grigoropoulos V, Theodossiadis P. Long-term changes of macular thickness after pars plana vitrectomy in optic disc pit maculopathy: a spectral-domain optical coherence tomography study. Semin Ophthalmol. 2017;32(3):302-308.

34. Teke MY, Citirik M. 23 Gauge vitrectomy, endolaser, and gas tamponade versus vitrectomy alone for serous macular detachment associated with optic disc pit. Am J Ophthalmol. 2015;160(4):779.e2-785.e2.

35. Rayat JS, Rudnisky CJ, Waite C, et al. Long-term outcomes for optic disk pit maculopathy after vitrectomy. Retina. 2015;35(10):2011-2017.

36. Avci R, Yilmaz S, Inan UU, et al. Long-term outcomes of pars plana vitrectomy without internal limiting membrane peeling for optic disc pit maculopathy. Eye. 2013;27(12):1359-1367.

37. Avci R, Kapran Z, Ozdek Ş, et al. Multicenter study of pars plana vitrectomy for optic disc pit maculopathy: MACPIT study. Eye. 2017;31(9): $1266-1273$

38. Bottoni F, Cereda M, Secondi R, Bochicchio S, Staurenghi G. Vitrectomy for optic disc pit maculopathy: a long-term follow-up study. Graefes Arch Clin Exp Ophthalmol. 2018;256(4):675-682.

39. Steel DHW, Suleman J, Murphy DC, Song A, Dodds S, Rees J. Optic disc pit maculopathy: a two-year nationwide prospective populationbased study. Ophthalmology. Epub 2018 Jun 7.

40. Steel DH, Williamson TH, Laidlaw DA, et al. Extent and location of intraretinal and subretinal fluid as prognostic factors for the outcome of patients with optic disk pit maculopathy. Retina. 2016;36(1): $110-118$.

41. Hara R, Tsukahara Y, Simoyama T, Mori S. Refined internal limiting membrane inverted flap technique for intractable macular detachment with optic disc pit. Case Rep Ophthalmol. 2017;8(1):208-213.

42. Sborgia G, Recchimurzo N, Sborgia L, et al. Inverted internal limiting membrane-flap technique for optic disk pit maculopathy: morphologic and functional analysis. Retin Cases Brief Rep. Epub 2018 Feb 22.

43. Theodossiadis GP, Chatziralli IP, Theodossiadis PG. Macular buckling in optic disc pit maculopathy in association with the origin of macular elevation: 13-year mean postoperative results. Eur J Ophthalmol. 2015;25(3):241-248.
44. Lincoff H, Yannuzzi L, Singerman L, Kreissig I, Fisher Y. Improvement in visual function after displacement of the retinal elevations emanating from optic pits. Arch Ophthalmol. 1993;111(8):1071-1079.

45. Akiyama H, Shimoda Y, Fukuchi M, et al. Intravitreal gas injection without vitrectomy for macular detachment associated with an optic disk pit. Retina. 2014;34(2):222-227.

46. Lei L, Li T, Ding X, et al. Gas tamponade combined with laser photocoagulation therapy for congenital optic disc pit maculopathy. Eye. 2015;29(1):106-114.

47. Theodossiadis GP. Treatment of maculopathy associated with optic disk pit by sponge explant. Am J Ophthalmol. 1996;121(6):630-637.

48. Theodossiadis GP, Theodossiadis PG. The macular buckling technique in the treatment of optic disk pit maculopathy. Semin Ophthalmol. 2000;15(2):108-115.

49. Theodossiadis GP, Theodossiadis PG. Optical coherence tomography in optic disk pit maculopathy treated by the macular buckling procedure. Am J Ophthalmol. 2001;132(2):184-190.

50. Georgopoulos GT, Theodossiadis PG, Kollia AC, Vergados J, Patsea EE, Theodossiadis GP. Visual field improvement after treatment of optic disk pit maculopathy with the macular buckling procedure. Retina. 1999; 19(5):370-377.

51. Ooto S, Mittra RA, Ridley ME, Spaide RF. Vitrectomy with inner retinal fenestration for optic disc pit maculopathy. Ophthalmology. 2014;121(9):1727-1733.

52. Inoue M, Shinoda K, Ishida S. Vitrectomy combined with glial tissue removal at the optic pit in a patient with optic disc pit maculopathy: a case report. J Med Case Rep. 2008;2:103.

53. Rosenthal G, Bartz-Schmidt KU, Walter P, Heimann K. Autologous platelet treatment for optic disc pit associated with persistent macular detachment. Graefes Arch Clin Exp Ophthalmol. 1998;236(2): 151-153.

54. Ozdek S, Ozdemir HB. A new technique with autologous fibrin for the treatment of persistent optic pit maculopathy. Retin Cases Brief Rep. 2017;11(1):75-78.

55. Todorich B, Sharma S, Vajzovic L. Successful repair of recurrent optic disk pit maculopathy with autologous platelet rich plasma: report of a surgical technique. Retin Cases Brief Rep. 2017;11(1):15-17.
Clinical Ophthalmology

\section{Publish your work in this journal}

Clinical Ophthalmology is an international, peer-reviewed journal covering all subspecialties within ophthalmology. Key topics include: Optometry; Visual science; Pharmacology and drug therapy in eye diseases; Basic Sciences; Primary and Secondary eye care; Patient Safety and Quality of Care Improvements. This journal is indexed on Submit your manuscript here: http://www.dovepress.com/clinical-ophthalmology-journal

\section{Dovepress}

PubMed Central and CAS, and is the official journal of The Society of Clinical Ophthalmology (SCO). The manuscript management system is completely online and includes a very quick and fair peer-review system, which is all easy to use. Visit http://www.dovepress.com/ testimonials.php to read real quotes from published authors. 